\title{
Editorial
}

Ali Baklouti*

\section{3rd Meeting of the Tunisian Mathematical Society (March 2018, Tabarka, Tunisia)}

https://doi.org/10.1515/apam-2019-2002

The 23rd edition of the annual congress of the Tunisian Mathematical Society (TMS) took place in Tabarka during March 19-22, 2018. The present volume collects some of the important contributions, subject of some plenary invited talks in the meeting and other contributed articles. Each paper submitted to the proceedings has been peer-reviewed through the standard process as an academic paper. The papers in this volume are all agreed upon publication with the referee, and necessary revisions, if any, have been made in the originally submitted manuscript.

The TMS organizes a five-day congress each year in a different Tunisian city, where Tunisian and foreign experts are invited to give lectures in different mathematical specialties. This congress is a valuable opportunity for Tunisian researchers, in Tunisia and abroad, to present their research work and interact with young doctoral students. The proceedings of the congress follow up on high-quality research articles published in an international peer-reviewed journal.

The TMS is a scholarly association that brings together researchers, professors and doctoral students in the field of mathematics research in Tunisia. It was founded in 1992 and it is now considered as one of the most prestigious mathematical associations in Africa. It plays a major role in stimulating and sustaining high-level mathematical research in Tunisia and its surrounding region. Its multiple objectives consists first in promoting the discovery, learning and application of mathematics, improving mathematics education through joint projects with mathematics teachers at all levels and in partnership with the Ministry of Higher Education and Scientific Research with support research in mathematics and democratize mathematics by putting in place initiatives to promote and raise awareness of the discipline.

The TMS brings together Tunisian mathematicians through the publication of a monthly newsletter and the sponsorship of various activities and develops partnerships with the Tunisian universities, companies and other mathematical associations in Tunisia and abroad. It interacts with several mathematical societies around the world and is bound by reciprocal agreements with many companies and mathematical sciences associations.

The TMS launched the Tunisian Journal of Mathematics, which is an international publication organized by the society and published in electronic and print formats by the Mathematical Sciences Publishers. It publishes research articles in all areas of mathematics. These will be selected by a distinguished, international board of editors based on outstanding quality and interest, and according to the highest international standards. With the launch of this journal, the TMS contributes to the development in Africa of the scientific research in mathematics, meeting high international standards. 